\title{
Os novos lugares ou dimensões do fazer manual na arte contemporânea
}

\author{
Flávia Vieira ${ }^{1}$ \\ Edson de Prado Pfützenreuter ${ }^{2}$
}

\section{Introdução}

REFLETIR SOBRE A ARTE CONTEMPORÂNEA A PARTIR DA IDEIA DE UM FAZER MANUAL poderá parece anacrônico numa época em que as discussões sobre a prática artística se voltam cada vez mais para os conceitos de imaterialidade e de virtualidade, e na qual assistimos ao crescimento progressivo do fenômeno da terceirização técnica num mercado capitalista onde proliferam meios de produção industrializados. Por outro lado, a tradição artística ocidental tem sido, em grande parte, marcada por um entendimento da arte a partir do objeto final, negligenciando os processos do fazer e, assim, limitando e obstruindo a discussão em torno desses processos $^{3}$. Contudo, existem formas de manifestação artística que exigem uma reflexão acerca de processos de criação ligados à manualidade na obra, não só como uma forma de reconfiguração matérica e plástica, mas também como uma forma de linguagem que pode refletir e potenciar uma crítica à globalização e ao excesso de consumo, bem como às narrativas do fazer atualmente dominantes. Se a desmaterialização da arte nos coloca o problema de rastrear os processos criativos, também é verdade que o lugar da manualidade na arte tem sido pouco reconhecido e estudado, o que coloca exatamente o mesmo problema. Em ambos os casos, podemos dizer que o processo está na obra, em cena mas também nos seus bastidores ou circuitos internos, importando investigar relações entre esses dois espaços.

O presente artigo, baseado no estudo de doutorado da primeira autora ${ }^{4}$, aborda os possíveis novos lugares ou dimensões do fazer manual na arte contemporânea a partir do testemunho e obras de dez artistas entrevistados: Alexandre da Cunha (Brasil), Arna Óttarsdóttir (Islândia), Brie Ruais (E.U.A.), Caroline Achaintre (França), Ingrid Wiener (Áustria), Jonathan Trayte (Reino Unido), Juliana Cerqueira Leite (Brasil), Luke Armitstead (E.U.A), Sônia Gomes (Brasil) e Tiago Mestre (Portugal). As entrevistas, de natureza semiestruturada, foram realizadas por email ou presencialmente, a partir de um roteiro de oito perguntas abertas, convidando os artistas a refletirem acerca da presença da manualidade na prática artística contemporânea, em

\footnotetext{
${ }^{1}$ Professora convidada do Departamento de Artes Visuais da Escola de Arquitetura, Arte e Design da Universidade do Minho, Portugal. Formação: Graduação em Artes Plásticas; Mestrado em Comunicação e Artes e Doutorado em Poéticas Visuais e Processos de Criação. Contato: fmfvieira@yahoo.com

${ }^{2}$ Professor do Instituto de Artes da Universidade Estadual de Campinas - UNICAMP, Brasil. Formação: Graduação em Artes Plásticas; Mestrado e Doutorado em Comunicação e Semiótica. Contato: reuter@unicamp.br

${ }^{3}$ A divisão entre o objeto final e os seus modos de produção encontra origens na tradição renascentista de inferiorização das tarefas ditas manuais em favor da dimensão intelectual, que foi sendo consolidada ao longo dos séculos, atingindo a sua máxima expressão no século XVIII, coincidindo com o confronto teórico e institucional entre as belas-artes e o artesanato, ou entre as artes maiores e as artes menores.

${ }^{4}$ Estudo intitulado O Artista Contemporâneo enquanto Artesão - A Presença do Fazer Manual na Arte realizado na área de Poéticas Visuais e Processos de Criação no Instituto de Artes da Universidade estadual de Campinas - UNICAMP, Brasil, com a orientação de Edson de Prado Pfützenreuter.
} 
particular, no seu próprio trabalho ${ }^{5}$. A escolha dos artistas obedeceu aos seguintes critérios: enquadramento do seu trabalho artístico na problematização do fazer manual na contemporaneidade; envolvimento físico com os processos do fazer das suas obras; regularidade da sua atividade em exposições, projetos e participação no mercado; e, finalmente, diversidade geográfica, abrangendo-se artistas de distintas nacionalidades (brasileira, norte-americana, britânica, francesa, islandesa, austríaca e portuguesa).

$\mathrm{O}$ artigo procura reconhecer e evidenciar o lugar da manualidade nos processos e objetos artísticos. Embora o trabalho de cada artista se constitua na sua particularidade, foram identificadas cinco dimensões do fazer manual que ilustramos no artigo: novos diálogos com o corpo, performance ou a "mão-em-ação", permanência do fazer tradicional manual, uso expandido das técnicas tradicionais e reivindicação de uma posição politizada do fazer.

\section{sobre o fazer manual na arte}

O fazer com as mãos, sendo uma das capacidades mais brilhantes do homem e uma das principais características do processo de hominização, representa uma arma vigorosa de participação na sociedade, resultante de uma conquista anatômica igualmente determinante e fascinante: a mão ${ }^{6}$. A mão determina os modos de interação táctil e cognitiva com o mundo que nos rodeia, nomeadamente como instrumento de mediação entre pensamento e ação, entre o eu e o outro.

Sendo a mão um instrumento de produção de bens culturais, pensar sobre a prática artística é também pensar sobre o seu fazer. Torna-se difícil entender o fenômeno artístico sem se considerar o modo como os artistas trabalham o seu processo criativo. Seja recorrendo a um procedimento mais tradicional, ou utilizando metodologias ou media mais atuais, num contexto de ateliê ou extrapolando os limites do espaço convencional de trabalho, o fazer impõe-se de variados modos, sendo determinante nos momentos da concepção e da percepção da obra de arte. Trata-se de enfatizar que "A maneira pela qual a obra foi produzida reflete-se no produto acabado. O modo como ela se mostra é o que chamamos de fature"

Segundo a curadora e teórica Martina Margetts, o fazer no processo criativo parte de um desejo interno do sujeito de se expressar, tendo, na sua ação, impacto não somente nele mesmo, como também no mundo:

(...) o fazer é a revelação do impulso humano para explorar e expressar formas de conhecimento e um conjunto de emoções; um impulso em direção ao conhecimento e ao sentimento que molda a ação humana e consequentemente o mundo que criamos. A recompensa do fazer é a oportunidade de experimentar um sentido individual de liberdade e controle no mundo. O fazer não é assim apenas uma satisfação de necessidades, mas de desejos - um processo através do qual a mente, o corpo e a imaginação estão integrados na prática do pensamento através da ação. ${ }^{8}$

\footnotetext{
${ }^{5}$ As entrevistas foram transcritas na íntegra, com autorização expressa dos artistas para a sua utilização na investigação realizada. As imagens das suas obras foram por eles cedidas ou são de domínio público.

${ }^{6}$ NAPIER, John Russell. Hands. New Jersey: Princeton University Press, 1980.

WILSON, Frank. The Hand: How its use shapes the brain, language, and human culture. USA: Vintage Books, 1998.

${ }^{7}$ ADAmson, Glenn. Thinking Through Craft. New York: Berg, 2007, p. 59. Tradução nossa.

${ }^{8}$ MargetTs, Martina. Action Not Words. In: Charny, Daniel (ed.). Power of Making: The importance of being skilled.

London: V\&A Publishing, p. 38-43, 2011, p. 39. Tradução nossa.
} 
Adamson e Bryan-Wilson ${ }^{9}$ apontam três razões que justificam a importância do estudo crítico das "narrativas do fazer" nas artes visuais. Primeiramente, o fazer determina o entendimento da obra. A relação do espectador com o objeto artístico depende, entre outros factores, das estratégias formais utilizadas e das pesquisas envolvidas nesse processo, assim como do conhecimento da autoria manual e intelectual das propostas, ou seja, de saber de quem são as mãos e as mentes que participaram na criação dos objetos. No que diz respeito aos meios de produção manual, os limites técnicos, construtivos e matéricos, bem como a habilidade ou destreza $(s k i l l)$, são condições fundamentais na definição do objeto. A este propósito, Adamson e Bryan-Wilson consideram que a diversidade dos meios de produção, independentemente da sua natureza, será a dimensão que melhor caracterizará a produção artística atual:

Quando os historiadores de arte futuros olharem para trás para o dia presente, é possível que o que mais os impressione seja a total proliferação da nossa arte, em vez do seu conteúdo. Nenhuma era criou tanta arte, ou arte tão eclética. A profusão da produção artística em toda a sua variedade é desconcertante, tanto que, além da sua expansão aparentemente imparável, parece impossível resumir as tendências da arte no último meio século. Parece não haver barreiras óbvias de aceitabilidade deixadas para romper. Ideias como a provocação de vanguarda, ou 'novidade', ou 'originalidade', tornaram-se clichés gastos para os artistas contemporâneos. ${ }^{10}$

A segunda razão apontada pelos autores prende-se à evidência do fazer enquanto modo de pensamento, isto é, o fazer como gerador de um conhecimento que é singular. $\mathrm{O}$ ato do fazer é poderoso, porque através dele produz-se significado e conhecimento experiencial tácito, através do qual "podemos saber mais do que podemos dizer e não podemos dizer nada sem confiar na nossa consciência das coisas que talvez não possamos dizer"11. Como refere McCullough, “(...) as mãos são a melhor fonte de conhecimento pessoal tácito porque, de todas as extensões do corpo, são as mais sutis, as mais sensíveis, as mais aprofundadas, as mais diferenciadas e as mais conectadas com a mente. Elas mereceram ser admiradas" ${ }^{\text {"12 }}$. Segundo Margetts, o fazer ocorre "na prática do pensamento através da ação":

O papel do fazer é assim dar vida às coisas, mas também mostrar a evidência da vida dentro de nós, talvez também num nível espiritual. O papel do fazer é uma sequência de ações que desencadeiam uma curiosidade para ir além do que já é conhecido, numa linguagem nãoverbal que amplia as nossas habilidades de comunicarmos uns com os outros ao longo das culturas, do tempo e do espaço. (...) o papel do fazer é criar novas formas de pensar, através do compromisso com os materiais, técnicas e ideias. ${ }^{13}$

Por último, Adamson e Bryan-Wilson ${ }^{14}$ sublinham a dimensão política da produção decorrente da teoria marxista, ou seja, a evidência da adoção intencional de meios de fabricação manual e artesanal como

\footnotetext{
9 ADAMSON, Glenn; BRYAN-WILSON, Julia. Art in the Making: Artists and their Materials from the Studio to Crowdsourcing. London: Thames \& Hudson, 2016.

${ }^{10}$ Ibidem, p. 9. Tradução nossa.

11 PolanYI, Michael. Personal Knowledge: Towards a Post-Critical Philosophy. New York: Harper \& Row, 1964, p. X. Tradução nossa.

${ }^{12}$ Mccullough, Malcolm. Abstracting Craft: The Practiced Digital Hand. Cambridge, Massachusetts e London: The MIT Press, 1996, p.7. Tradução nossa.

${ }^{13}$ MARGETTS, op. cit, p. 43. Tradução nossa.

${ }^{14}$ ADAMSON; BRYAN-WILSON, op.cit.
} 
manifesto e posicionamento político sobre a produção massificada e globalizada que atingiu a arte. Sob uma perspectiva politizada, Crawford ${ }^{15}$ propõe um reposicionamento da separação hierárquica entre os trabalhadores de colarinho azul e os de colarinho branco no contexto laboral, bem como uma reavaliação do sistema de educação que atualmente privilegia o conhecimento intelectual sobre o conhecimento prático e do know-how. $\mathrm{O}$ autor é enfático na satisfação que pode ser gerada no envolvimento do sujeito com o mundo físico e do conhecimento gerado através do toque, num contexto em que a inovação tecnológica amortece os nossos sentidos e consome a nossa vitalidade:

Queremos sentir que o nosso mundo é inteligível, para que possamos nos sentir responsáveis por isso. Isso parece exigir que a proveniência das nossas coisas seja trazida para mais perto de casa. Muitas pessoas estão tentando recuperar um campo de visão que é basicamente humano em escala, e se livrar da dependência das forças obscuras de uma economia global. ${ }^{16}$

Apesar de se reconhecer as infinitas vantagens do desenvolvimento tecnológico e digital no mundo atual, a abundância de informação e de novas possibilidades, por mais eficientemente construídas e usadas, pode deixar-nos também num estado de insatisfação que nos poderá despertar o desejo, talvez fisiologicamente enraizado, de usar as nossas mãos de formas mais variadas - em suma, de sentir novamente. Citando Maria Elena Buszek:

$\mathrm{Na}$ atual era da informação, a 'informação’ sensual e tátil dos meios artesanais fala (...) de uma conexão direta com a humanidade que talvez esteja ameaçada ou, no mínimo, rapidamente reconfigurada nas nossas vidas tecnologicamente saturadas do século XXI - o que demonstra o extraordinário potencial desses meios e processos aparentemente vulgares. ${ }^{17}$

Ao reconfigurar as narrativas convencionais de produção artesanal através da escolha deliberada de modos de fazer lentos, comprometidos e (auto)expressivos, os artistas reclamam e postulam uma presença ativa e participativa na produção da obra. Considerando que o objeto artístico é uma manifestação cultural tradutora de um determinado contexto, contemplar reflexivamente os bastidores de produção é também ter a possibilidade de construir uma visão crítica sobre a atuação humana no mundo e sobre os seus modos de funcionamento cultural, social e político.

\section{Dimensões do fazer manual na arte contemporânea}

\section{Novos diálogos com o corpo}

A partir das entrevistas realizadas e da análise dos trabalhos dos artistas convidados, compreendemos que a dimensão do fazer manual na arte contemporânea manifesta-se através de novas relações com o corpo. A mão expandida torna-se amplamente presente no processo criativo e é parte integrante no entendimento final

\footnotetext{
${ }^{15}$ CRAWFORD, Matthew. The Case for Working with Your Hands. London: Penguin, 2009.

${ }^{16}$ Ibidem, p. 8. Tradução nossa.

${ }^{17}$ BuszeK, Elena (ed.). Extra/Ordinary - Craft and Contemporary Art. Durham, London: Duke University Press, 2011, p.1. Tradução nossa.
} 
do trabalho. Esta estratégia deixa adivinhar um entendimento corporificado da obra ${ }^{18}$, na qual a consciência corporal é despertada e é desencadeado um processo de percepção em que a visão e o tato trabalham paralela e empaticamente. Tocamos com os olhos e vemos com as mãos.

O trabalho da artista visual norte-americana Brie Ruais representa um exemplo da importância do corpo e da experiência háptica de relação direta entre o corpo e a matéria da argila no processo criativo. Utilizando três parâmetros básicos de orientação - uma quantidade de argila igual ao peso do seu corpo, um conjunto específico de instruções autoimpostas e o uso do seu próprio corpo como ferramenta -, desenvolve um conjunto de ações corporais sobre a argila como bater, esmurrar, amassar, espalhar, contorcer ou dobrar, formando registros da especificidade do seu próprio corpo na matéria. Durante a entrevista, a artista manifesta a importância do corpo no seu trabalho: "O meu trabalho é sobre a experiência física do ser. A melhor maneira que eu encontrei para expressar isso é trabalhar com um material que capta isso física e conceitualmente.” Refere também que "As pessoas deixam rastos e cicatrizes em tudo o que tocam enquanto se movem pela vida. Somos mais do que a nossa mente, somos também corpos"19.

A obra "Corner Push (White)" (figura 1) é um exemplo da importância do corpo e da experiência háptica no processo criativo de Brie Ruais. A proposta resulta do movimento das pernas que empurram e pontapeiam a argila crua contra a parede até atingir a altura máxima (figura 2). Cria-se uma espécie de segundo corpo, um correlato do corpo da artista, porém disforme.

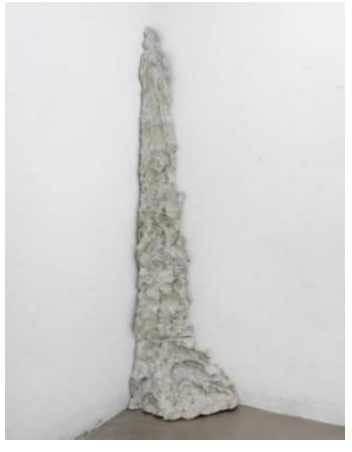

Figura 1: Brie Ruais, "Corner Push (White)". cerâmica vidrada, 59kg de argila, 190.5 x 40.64 x 35.56 cm, 2014. Fonte: https://artviewer.org/wp-content/uploads/ 2015/06/9.CC_Brie_Ruais_Corner_Push_White-1.jpg

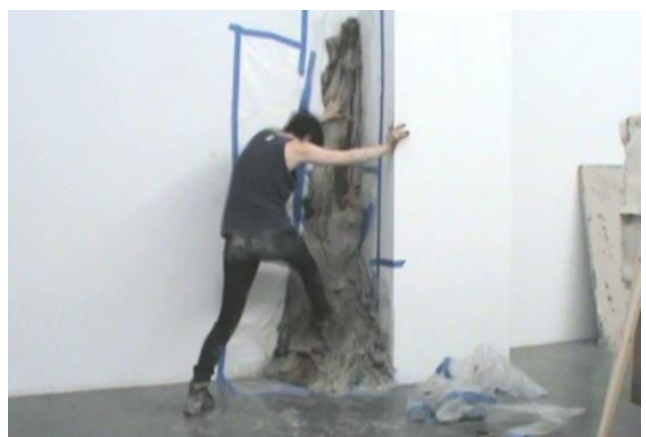

Figura 2: Brie Ruais construindo a obra “Corner Push (White)”, 2014. Fonte: http://www.chrismurtha.com/vessels

Procurando explorar os limites do corpo em relação à matéria da argila, Ruais envolve-se num processo trabalhoso, repetitivo e intensamente vivido, no qual a argila registra arqueologicamente o seu corpo e este ocupa um determinado espaço. Citando a artista na sua entrevista:

O parâmetro principal é que quase sempre trabalho com o peso do meu corpo em argila cerca de $58 \mathrm{~kg}$. A razão para isso é baseada na escala. Se eu quiser gravar os gestos e os movimentos do meu corpo inteiro, eu meio que tenho que fazer a coisa grande. E usar a

\footnotetext{
${ }^{18}$ Merleau-Ponty, Maurice. Fenomenologia da Percepção. São Paulo: Martins Fontes, 1999.

${ }^{19}$ VIEIRA, Flávia. O Artista Contemporâneo enquanto Artesão - A Presença do Fazer Manual na Arte. 2019. Tese (Doutorado em Artes Visuais) - Instituto de Artes, Universidade Estadual de Campinas, Campinas, 2019, p. 332. Tradução nossa.

Todos os excertos de entrevistas são retirados da tese de doutorado da primeira autora. As entrevistas podem ser consultadas na íntegra nesse estudo.
} 
unidade do meu peso corporal cria uma dinâmica entre mim e o material, que se torna um diálogo. É tanto material que eu não consigo estar totalmente no controle dele. É resistente; nunca é um processo fácil, se você sabe o que quero dizer. Está sempre empurrando de volta. ${ }^{20}$

De modo análogo, a artista visual brasileira Juliana Cerqueira Leite, que vive e trabalha em Nova Iorque, convoca para a sua prática uma experiência háptica íntima da relação do seu corpo com a matéria, construindo uma espécie de "coreografia" 21 . As suas esculturas táteis e de grande escala revelam um discurso sobre as habilidades e os constrangimentos do corpo humano. Usando o seu próprio corpo como ferramenta primária, Juliana Cerqueira Leite amassa, escava, arranha, empurra ou ergue os seus materiais - que incluem argila, látex e gesso - para criar formas orgânicas. As esculturas retêm as impressões das suas mãos, braços e pernas e ganham uma aparência semelhante à matéria do corpo como pele e osso. Afirma na entrevista: "Os processos manuais que uso são íntimos. Eu costumo usar o meu corpo como molde/forma para os trabalhos, iniciando uma temporalidade específica: a do que eu posso fazer. (...) Lemos o corpo e os movimentos de quem fez o trabalho"22.

A obra escultórica "H2" (figuras 3 e 4), produzida no âmbito de uma residência artística em Veneza em 2017, evidencia a experiência háptica íntima da relação do seu corpo com a matéria. Depositando várias camadas de moldes com diferentes cores sobre o seu corpo, as esculturas mostram as suas impressões digitais, as suas pegadas, a forma do seu tornozelo, o desenho do seu joelho, o seu peso através de depressões... - em suma, a sua identidade física. As poses adotadas neste trabalho tornam-se uma coreografia que é fixada no tempo e no espaço, e somos confrontados com uma manifestação visual da memória da presença.
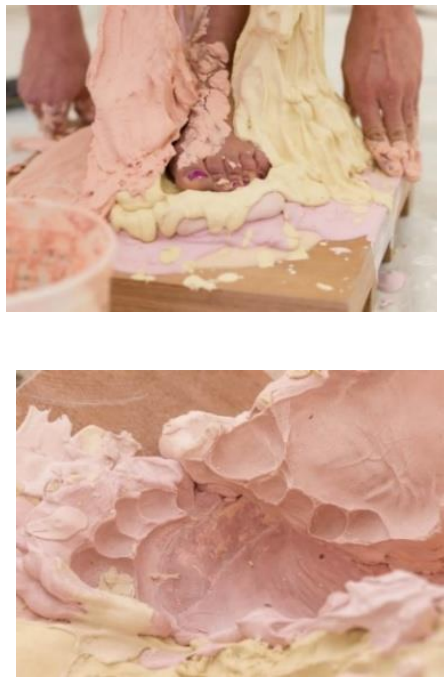

Figura 3: Documentação da produção de "H2", Figura 4: Juliana Cerqueira Leite, "H2", hidrocal, aço 2017. Fonte:

https://www.julianacerqueiraleite.com/h2-2017

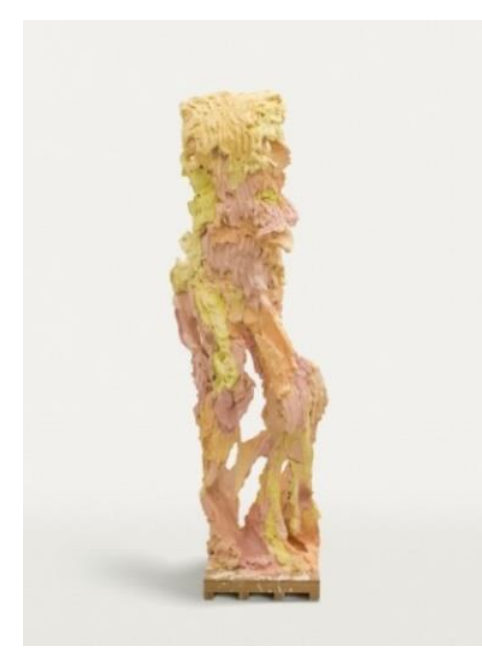

e pigmento, 2017. Fonte:

https://www.julianacerqueiraleite.com/h2-2017

\footnotetext{
${ }^{20}$ ABRAMS, Loney. Sculpting the Landscape: Brie Ruais on Using Clay as a Metaphor for Land's Violent History. Artspace: Artspace, Brooklyn, 28 set. 2017. Disponível em: https://www.artspace.com/magazine/interviews_features/qa/sculptingthelandscape-brie-ruais-on-using-clay-as-a-metaphor-for-lands-violent-history-55026. Acesso em: 6 mar. 2018. Tradução nossa.

${ }^{21}$ VIEIRA, op cit., p. 337.

${ }^{22}$ Ibidem, p. 337.
} 
As esculturas amorfas de Ruais e de Cerqueira Leite contam a história de um corpo antes presente e agora ausente. Esse rastro da presença do corpo na obra, que lhe atribuiu uma dimensão corporificada à escala humana, pode ser interpretado como um comentário crítico à sociedade ocidental despersonalizada e desincorporificada. Assim, a presença corporal associada ao fazer manual afirma e denuncia um "eu" abandonado e subvalorizado. As marcas corporais remetem para um processo criativo que reclama a presença do autor enquanto sujeito.

\section{Performance - "mão-em-ação"}

Segundo a curadora francesa, Valerie Cassel Olivier, que comissariou a exposição "Hand+Made: The Performative Impulse in Art and Craft" no Contemporary Arts Museum Houston, "O artesanato está intrinsecamente ligado à performance" ${ }^{23}$. Ou tal como refere Adamson, "O artesanato apenas existe em movimento. É um modo de fazer coisas, e não uma classificação de objetos, instituições, ou pessoas” "24. Muitos artistas contemporâneos usaram e integraram a performance não somente como um catalisador para a produção de objetos, mas também como um meio tanto para implodir a tradição como para gerar novas práticas e sentidos ${ }^{25}$.

No contexto do estudo realizado, destacamos novamente o trabalho desenvolvido pela artista Brie Ruais, cujos trabalhos resultam de um registro performático físico do corpo através da matéria da argila. Mais do que esculturas, os seus trabalhos apresentam-se como documentos de uma ação, um pouco à semelhança das pinturas de Jackson Pollock que resultavam de um processo performático do fazer - o action painting. A similitude com o Expressionismo Abstracto de Pollock também se prende com um dos métodos usados pela artista: a produção da obra no plano horizontal para, depois do material secar, passar para o plano vertical. Parece-nos que, tal como Pollock desafiava o entendimento da pintura das primeiras décadas do século XX retirando-a do plano da parede e atribuindo mais ênfase aos processos do fazer, também Ruais encontra um novo lugar para a cerâmica evidenciando a sua dimensão performática.

O trabalho do artista português Tiago Mestre é também um exemplo da integração dessa dimensão performática. Trabalhando principalmente com argila, destacamos o projeto "All the Things you Are" de 2014 (figuras 5 e 6) como representativo de uma abordagem processual em que a ação ocupa um lugar determinante no entendimento da obra. Desafiando-se a construir 21 esculturas num período de 21 dias a partir do mesmo pedaço de argila, o artista viu-se diariamente confrontado com a tentativa de se desprender do que era construído para pensar em novas configurações plásticas, expondo cada uma das suas obras ao longo desse período na vitrine da galeria Kunsthalle (São Paulo).

\footnotetext{
${ }^{23}$ OLIVIER, Valerie Cassel (ed.). Hand+Made: The Performative Impulse in Art and Craft. New York: Contemporary Arts Museum, Houston, 2010. Tradução nossa.

${ }^{24}$ ADAMSON, op. cit., p. 4. Tradução nossa.

${ }^{25}$ A presença da dimensão performática torna-se clara e enfática nas demonstrações públicas e nos workshops do artistaartesão Peter Voulkos nas décadas de 1960 e 1970. Numa espécie de action painting com argila, Voulkos transforma a sua escultura num ato performativo com movimentos extravagantes. Enfatizando o processo do fazer da obra aliado aos conceitos de mudança e de transformação, o artista procura enfatizar o conceito de facture.
} 


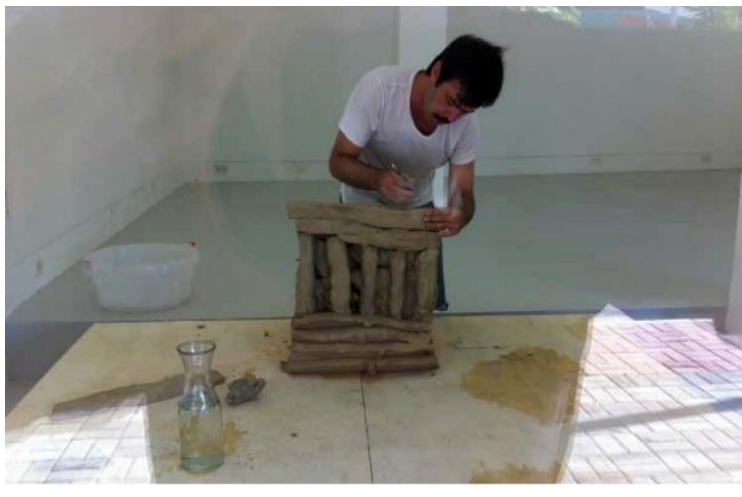

Figura 5: Registro fotográfico de Tiago Mestre construindo "All the Things you Are" in loco. Oitavo dia / oitava escultura, Kunsthalle São Paulo, 2014. Fonte: Imagem cedida pelo artista.

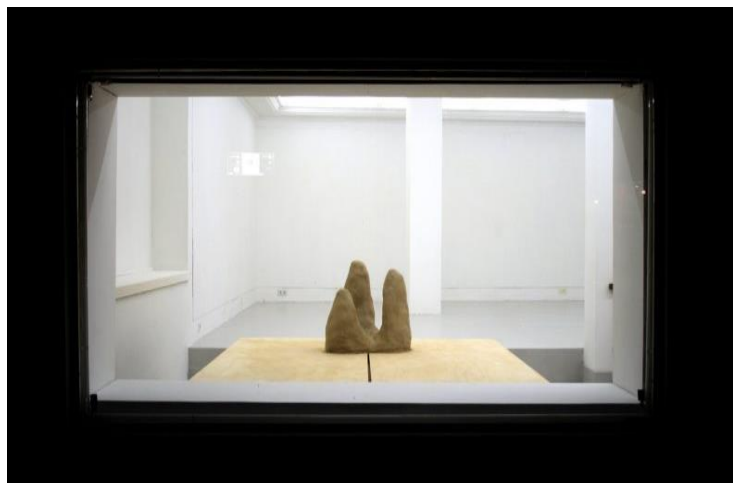

Figura 6: Tiago Mestre, "All the Things you Are", instalação, curadoria de Marina Coelho, Kunsthalle São Paulo, 2014. Fonte: Imagem cedida pelo artista.

Assim, mais do que procurar fixar e preservar o objeto final, Mestre encontra no fazer a sua potência plástica e conceitual, levantando com isso problemáticas do foro pessoal, uma vez que o trabalho funciona como uma espécie de metáfora da condição humana em permanente mutação, mas também relativas ao valor de mercado do objeto artístico contemporâneo, aqui questionado por propostas tão perecíveis e transitórias. Na entrevista, o artista evidencia a importância do ato do fazer nas suas obras:

Julgo que o meu trabalho tem uma dimensão única, que atravessa todas as obras, e que se poderia definir como uma evidenciação da manualidade e do ato do fazer. A performatividade do meu corpo, ou da minha mão, sempre é tido em conta, mas sempre de um modo implícito. Acho que o trabalho tem uma aptidão para evidenciar esse 'estar ali' pensando com o material e, posteriormente, 'deixar de estar'. A ação, a circunstancialidade do fazer, a escala da mão e do gesto, a coloquialidade do encontro com o material tornam-se, muitas das vezes, performatividade inerente à obra final. ${ }^{26}$

As esculturas de Ruais e de Mestre depreendem a presença de uma mão-em-ação, cuja existência surge nas impressões da matéria. Neste sentido, poderá dizer-se que o seu trabalho não é tanto sobre o objeto, mas sim sobre a narrativa do fazer, evidenciando a dimensão prática accional da obra, mas também a identidade do artista. Este adquire visibilidade e reforça o seu sentido de presença, como verificámos na secção relativa aos novos diálogos com o corpo. Essa presença é pautada por uma pró-atividade do artista que, a partir de ações, propõe uma reflexão sobre as narrativas do fazer que evidenciam o seu processo criativo. Tornar-se visível é tornar-se presente e real e, por conseguinte, participante e interveniente na materialização da obra.

\section{Fazer tradicional manual}

Num período em que a produção artística é frequentemente delegada a técnicos e artesãos especializados, encontramos também a opção por uma prática manual com recurso a meios tradicionais em que o conhecimento é adquirido durante o fazer, ou seja, orientada pela prática e por processos de reflexão-em-ação. A partir do estudo, compreendemos que alguns dos artistas utilizam processos artesanais de modo consciente e participam ativamente na

\footnotetext{
${ }^{26}$ VIEIRA, op. cit., p. 342.
} 
produção dos seus trabalhos como um meio de potencializar a sua prática do ponto de vista técnico e, com isso, explorar novas possibilidades conceituais.

O artista visual norte-americano Luke Armitstead, cujo trabalho se insere essencialmente na prática da cerâmica, refere na sua entrevista que o seu aprendizado com o material da argila é resultante da sua prática:

Eu sinto que aprendi muito através da natureza direta e verdadeira da argila, e através da minha maneira única de cavar profundamente no meu processo de fazer com a argila. Com o passar do tempo e com a aprendizagem do meu processo específico, as minhas habilidades de trabalho têm-se desenvolvido e crescido para novos níveis de compreensão e invenção. ${ }^{27}$

Percebemos que o seu trabalho é marcadamente orientado pela prática (practice-led) e que é nesse seu envolvimento com o fazer que se desenvolvem processos de aprendizado e, por conseguinte, progressos e transformações positivas no seu trabalho. As figuras 7, 8 e 9 documentam alguns processos de produção utilizados, como a manipulação manual da argila e a queima da mesma num forno de cerâmica, não parecendo existir uma diferença significativa da prática do artesão ceramista. As suas propostas artísticas partem de um conhecimento e de um discurso do artesanato, ou seja, trazem o conhecimento artesanal da cerâmica para a escultura. Inclusivamente, o artista não encontra nenhum obstáculo em ser equiparado a um artesão, sendo frequentemente entendido como um oleiro, embora reconheça que procura afirmar-se como um artista contemporâneo. Considera que o seu trabalho regular no meio da cerâmica tem gerado um conhecimento técnico muito superior e, com isso, uma diversidade de possibilidades plásticas que só o fazer manual faculta.

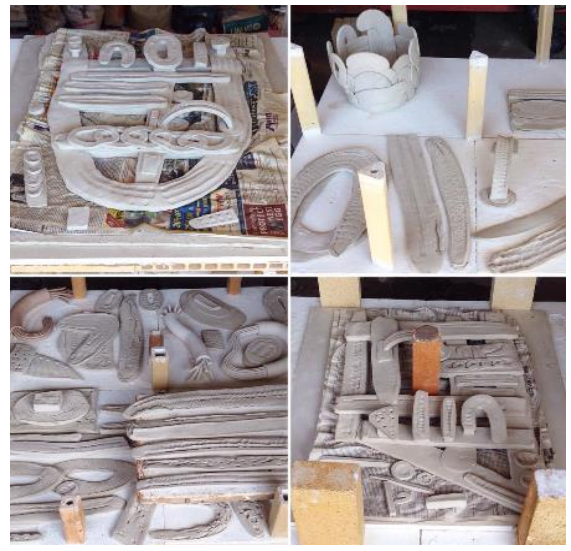

Figura 7: Registro fotográfico da mesa de trabalho no ateliê de Luke Armitstead, Seattle. Fonte:

https://www.instagram.com/p/BHNuBo TjDhK/

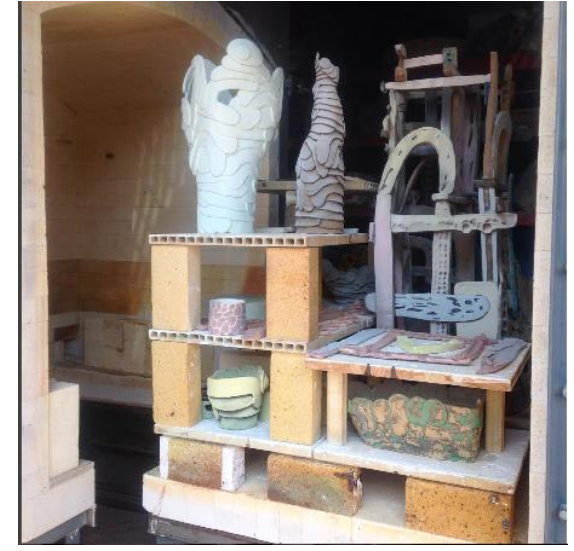

Figura 8: Registro fotográfico do forno no qual Luke Armitstead queima as suas esculturas de argila. Fonte:

https://www.instagram.com/p/BXQ3ol0A wUT/

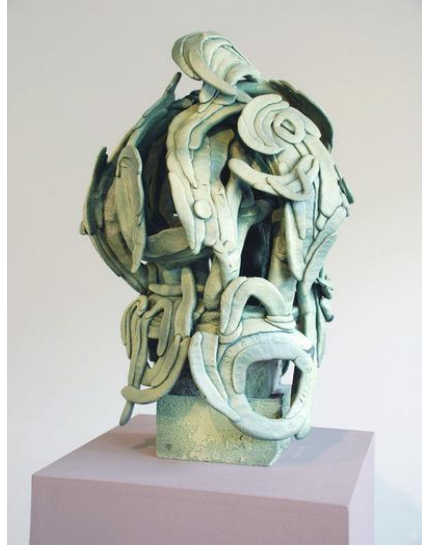

Figura 9: Luke Armitstead, "Green Helmet", cerâmica vidrada, 40 × 30 × $30 \mathrm{~cm}, 2015$. Fonte:

https://force.artsy.net/artist/lu ke-armitstead/related-artists

Citando o artista na entrevista:

Eu diria que os processos manuais dentro do meu fazer potenciam o meu trabalho adicionando um sentido de detalhe, de verdade, de complexidade, e de empatia. Existe um sentido de

\footnotetext{
${ }^{27}$ Ibidem, p. 339. Tradução nossa.
} 
manipulação que pode acontecer com a argila que permite que quase tudo seja construído. Eu aprecio a diversidade que se pode ter com a mão, a mesa, e as ferramentas com que se trabalha. Há algo que vai sempre além do computador. ${ }^{28}$

Os termos "verdade" e "empatia" usados para descrever os processos manuais remetem para um sentido de autenticidade, existência e identidade do trabalho. Apesar de reconhecer a importância da tecnologia ${ }^{29}$, o artista encontra no trabalho com a argila um veículo de conhecimento, acreditando que possa ser acolhido no meio artístico, apesar de admitir que se trata de uma luta constante:

As pessoas estão atualmente aprendendo muito com os computadores, eles podem ajudar muito! No entanto, estou atualmente aprendendo muito com a argila. Às vezes sinto que estou lutando contra a norma no meu trabalho. Porém, acredito que este contraste seja bom. (...) Eu luto permanentemente e estou certo de que outras pessoas também lutam para encontrar um caminho para que a nossa arte [da cerâmica] se encaixe neste mundo. Eu pergunto-me todos os dias como eu posso fazer isso. ${ }^{30}$

Também o trabalho do artista britânico Jonathan Trayte exprime um comprometimento com a prática da cerâmica e da fundição. À semelhança de Armitstead, Jonathan Trayte é o produtor das suas obras, mesmo daquelas que envolvem procedimentos tão complexos como os de fundição em bronze e em alumínio. A figura 10 documenta procedimentos implicados nas técnicas de molde, de fundição em bronze e alumínio, e de pintura sobre estes metais, que resultam em esculturas como a da figura 11, construída em bronze pelo próprio artista.
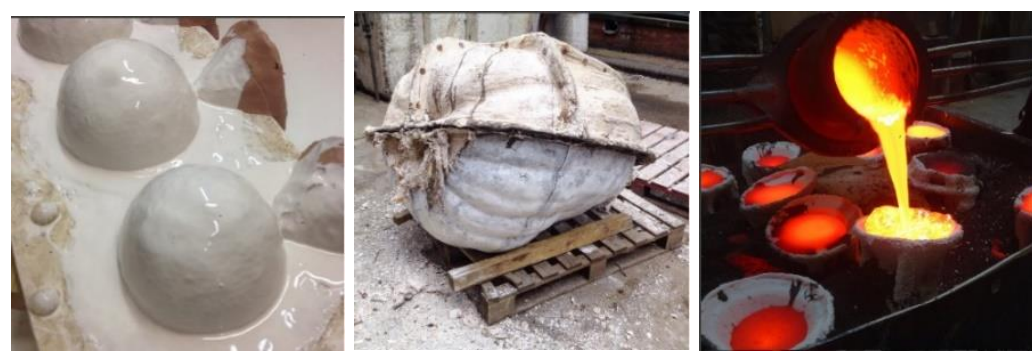

Figura 10: Registro fotográfico de Jonathan Trayte no seu ateliê em Londres: produção de moldes em gesso / produção de bronzes e alumínios. Fonte: https://www.instagram.com/p/BRHJIOxgFDr/ https://www.instagram.com/p/BGwNfbmDTrT/ https://www.instagram.com/p/BRV9WV9Dovt/

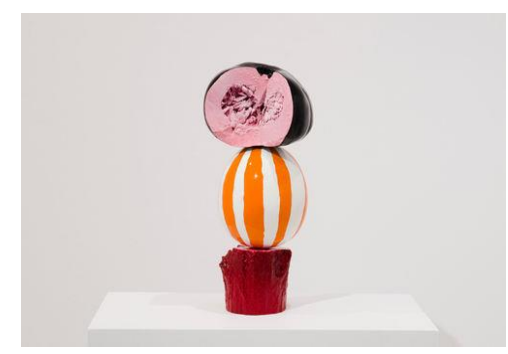

Figura 11: Jonathan Trayte, "Night Shift Nurse", pintura sobre bronze, 37 x 17 x 17 cm, 2012. Fonte: https://www.artslant.com/global/ar tists/show/55907-jonathantrayte?tab=PROFILE

Tendo aprendido com artesãos, Trayte manifesta-se como um artista fazedor que sempre se interessou pelos meios do fazer, o que para este ele parece constituir uma forma de desenvolver uma linguagem e progredir

\footnotetext{
${ }^{28}$ Ibidem, p. 338. Tradução nossa.

${ }^{29}$ Entenda-se aqui o termo "tecnologia" enquanto estudo sistemático sobre técnicas, processos, métodos, meios e instrumentos da prática da cerâmica. O termo pode englobar tanto técnicas tradicionais, como técnicas inovadoras e contemporâneas relacionadas ao desenvolvimento tecnológico.

${ }^{30}$ VIEIRA, op. cit., p. 339. Tradução nossa.
} 
no seu trabalho, implicando envolvimento e entrega, em contraste com uma "arte medíocre" baseada no espetaculoso e no facilitismo:

Eu valorizo o trabalho manual, e talvez seja apenas eu ficando um pouco mais velho (37 anos), mas parece que agora há tanta arte medíocre por aí. Tantos artistas estão clamando por atenção e os mais barulhentos nem sempre são os melhores. Às vezes eu realmente tenho muita dificuldade em apreciar um trabalho que é feito de qualquer jeito. Há mérito num gesto rápido, mas acho que muitas das novas galerias apoiam arte vistosa feita por artistas muito jovens que ainda não têm muito a dizer. Todos vestem o terno como se fossem roupas de novos imperadores, e as feiras internacionais apenas reforçam isso. Leva tempo para desenvolver uma linguagem e espero ter uma carreira de longo prazo que leve anos para se desenvolver. $^{31}$

O trabalho da artista islandesa Arna Óttarsdóttir reflete igualmente um interesse pelo uso de procedimentos tradicionais. Através de um tear manual de pedal (figura 12) e de um tear vertical de baixo liço (figura 13), a artista constrói pacientemente as suas tecelagens.

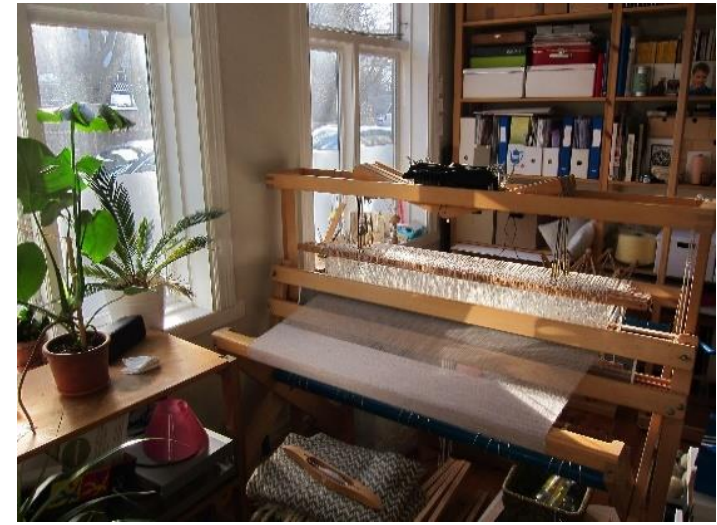

Figura 12: Registro fotográfico do tear de pedal no ateliê de Arna Óttarsdóttir, Islândia - Reykjavik. Fonte: Imagem cedida pela artista.

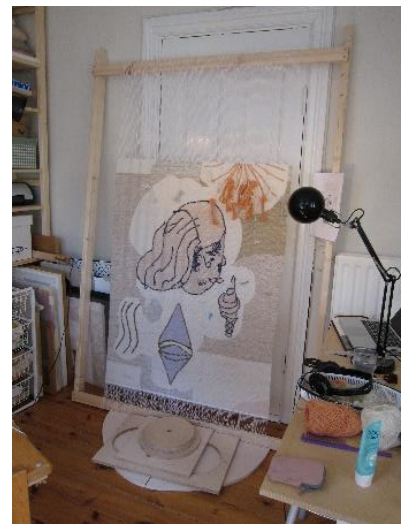

Figura 13: Registro fotográfico do tear vertical de baixo liço no ateliê de Arna Óttarsdóttir, Islândia - Reykjavik. Fonte: Imagem cedida pela artista.

É através do fazer prático que a sua obra se constitui, tanto do ponto de vista formal, como do ponto de vista conceitual. As tecelagens ilustram um fazer orientado pela prática e por processos de reflexão-em-ação, traduzindo uma atenção aos meios do fazer manual e à história agregada a estes. Apesar de admitir que gostaria de ter mais conhecimento sobre a tecnologia utilizada, a artista reconhece que a escolha do meio é determinante na leitura da obra:

Eu realmente não sei muito sobre tecelagem sendo que sou autodidata, então não acho que estou realmente ciente de todas as possibilidades dos processos de tecelagem, apesar de querer saber mais. E também não sei muito sobre a história da tecelagem e sobre arte têxtil, sobre a

${ }^{31}$ Ibidem, p. 336. Tradução nossa. 
qual também gostaria de aprender mais! (...) Mas fica claro que, de alguma maneira, o medium informa o trabalho. ${ }^{32}$

Nas propostas apresentadas, orientadas pela prática e por processos de reflexão-em-ação, o uso de tecnologias tradicionais está longe de ser uma conduta passiva focada na técnica, envolvendo também uma dimensão intelectual. O fazer técnico é explorado de um modo consciente e estratégico que embasa os propósitos discursivos formulados pelos artistas. As razões que os motivam a resgatar técnicas tradicionais convergem num sentido de autenticidade e entrega, de conexão empática e existencial com o trabalho, de engajamento e (auto)conhecimento. Este posicionamento destaca a individualidade e a presença do artista, que reafirma a sua existência corporal, mas também temporal, de cada vez que imprime a marca das suas mãos na obra de arte por meio de saberes e fazeres artesanais.

\section{Técnicas tradicionais manuais expandidas}

A partir das entrevistas realizadas, compreendemos que a dimensão do fazer manual na arte contemporânea manifesta-se através do uso expandido ${ }^{33}$ dos meios tradicionais manuais. As propostas seguidamente apresentadas procuram desafiar os limites do fazer manual associado aos meios tradicionais, mostrando com isso que a técnica manual pode ser ela mesma um meio ativo de subversão e impulsionar um pensamento crítico.

O trabalho da artista brasileira Sônia Gomes é elucidativo desta problemática pelo uso expandido do bordado e da costura através da subversão das técnicas e da incorporação de materiais inesperados, como a madeira e o arame, ou até mesmo objetos como gaiolas. Por conseguinte, o seu trabalho adquire um sentido escultórico e tridimensional. Isto porque, segundo a artista, "O tecido é muito plástico (...)"34 e é essa descoberta da plasticidade que lhe permite operar com maior liberdade. Recorrendo a meios muito precários como uma máquina de costura e a algumas ferramentas adicionais, constrói as suas esculturas de tecido e bordado numa constante procura de novas e distintas soluções.

O trabalho "Maria dos Anjos" (figuras 14 e 15), apresentado na Bienal do Mercosul de 2018, resulta de um vestido de noiva doado (procedimento habitual no seu trabalho) de uma mulher chamada Maria dos Anjos, do interior do Estado do Rio de Janeiro, e que o guardava por cinquenta anos. O tecido do qual é feita a obra acumula a história e a biografia dessa mulher, e marca o momento específico da sua união matrimonial. A partir de novas soluções formais com cortes e amarrações, a artista desconstrói a memória inerente a esse tecido e apresenta uma nova história, uma nova existência, uma nova vida a partir de memórias afetivas.

\footnotetext{
${ }^{32}$ Ibidem, p.330. Tradução nossa.

33 Apropriamo-nos da expressão "campo expandido" (1979) de Rosalind Krauss no artigo "Sculpture in the Expanded Field", October, vol. 8, 1979, The MIT Press, pp. 30 - 44, consultado em KRAUSS, Rosalind. 1985, pp. 276-290.

${ }^{34}$ GOMES apud PINTO, 2017.
} 


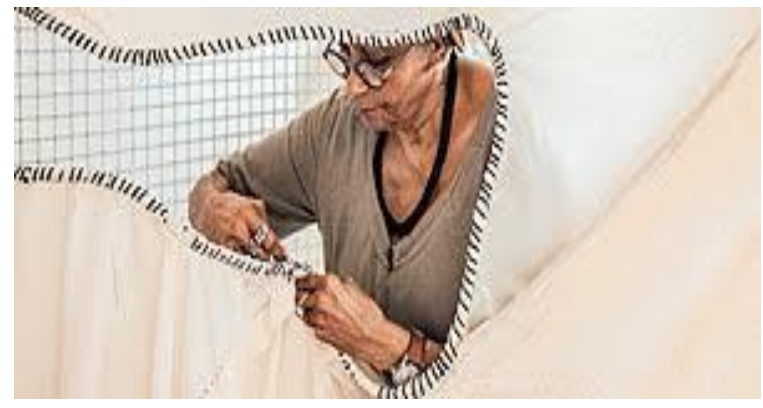

Figura 14: Sônia Gomes no seu ateliê, São Paulo, 2017. Fonte: https://www1.folha.uol.com.br/ilustrada/2017/12/1944244a-artista-e-mulher-e-negra-mas-arte-e-arte-diz-soniagomes.shtml

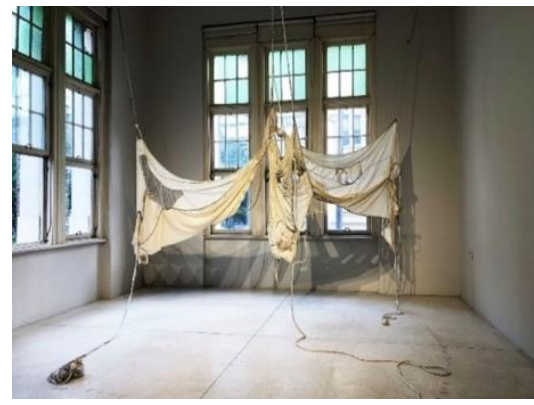

Figura 15: Sônia Gomes, "Maria dos Anjos”, Bienal do Mercosul, 2018. Fonte:

https://amlatina.contemporaryand.com/pt/editorial/me rcosul-biennial/

$\mathrm{Na}$ entrevista, a artista sublinha a importância do fazer manual, e, embora se distancie do artesanato, reconhece que parte dele. Refere o lado "mais humano e exclusivo" da manualidade, o que explica o modo como o seu trabalho incorpora a vida de outras pessoas, e também o seu sentido "poético" que exige o recurso a materiais diversificados:

Eu me aproprio de materiais que foram feitos à mão. Os bordados, os crochês, ... sou eu que faço. Era eu que pegava sempre, mas, à medida em que fui mostrando o trabalho em exposições, o material começou a chegar. Então as pessoas começam a ver partes delas nas obras: “- Olha gente, um botão do vestido da minha avó.” Isso era recorrente em Belo Horizonte porque eu conhecia muita gente e muita gente ia às minhas exposições. (...) $\mathrm{O}$ meu trabalho é poético, então para construir essa poética eu preciso de ter uma gama de material disponível. $^{35}$

A natureza "poética" do seu trabalho encontra-se também nas suas referências culturais. As volumétricas amarrações, nós e torções de tecido remetem à cultura afro-brasileira (como a folia de reis, congo, reisado) e ao catolicismo mágico, no qual os materiais se acumulavam e se sobrepunham, bem como às tradições africanas, cujo tecido é a base expressiva que permite simbolizações culturais como a presentificação da ausência por meio da roupa, o que ocorre com os Eguns no Benim e no culto de Baba Egun da Bahia. Por outro lado, as amarrações remetem às práticas do Candomblé, e os bordados evocam a cultura dos bordados de Minas Gerais, estado esse onde a artista nasceu.

O trabalho da artista francesa Caroline Achaintre é também representativo do uso expandido dos meios tradicionais manuais. Tendo como influência o universo do Expressionismo Alemão, da escultura britânica do pós-guerra, bem como do Primitivismo do início do século XX, a artista encontra nestas referências junções entre o antigo e o moderno, o psicológico e o físico, a realidade e o fantástico, o exotismo e a tecnologia. Estas relações dicotômicas são abordadas no seu trabalho pelo uso de uma iconografia atual sobre os meios tradicionais da tapeçaria e da cerâmica. As suas tapeçarias, produzidas com a ferramenta tufting gun (figuras $16 \mathrm{e}$ 17), transformam-se em pinturas. Sob uma base de lona, a artista vai tufando com a lã, num processo construtivo comparável a uma pintura que no lugar da tinta utiliza a lã e no lugar do pincel utiliza a tufting gun. Esta "pintura" adquire um carácter escultórico pela fisicalidade e materialidade da lã. Embora o processo de produção seja

${ }^{35}$ VIEIRA, op. cit., p. 340. 
bastante técnico, o trabalho é desenvolvido de maneira espontânea, e uma vez que a lã é tufada do lado de trás da tela, as composições são desenvolvidas sem uma previsão exata do resultado.

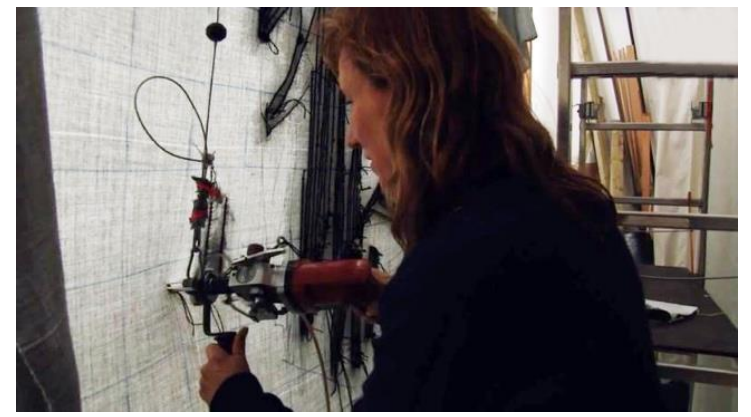

Figura 16: Caroline Achaintre no seu ateliê em Londres utilizando a ferramenta tufting gun na produção dos seus objetos. Fonte: https://vimeo.com/174540826. Still frame

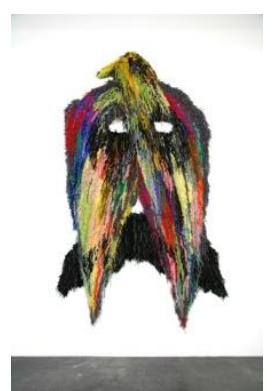

Figura 17: Caroline Achaintre, "Moustache-Eagle", lã tufada, 235 x $150 \mathrm{~cm}, 2008$. Fonte: https://aestheticamagazine.com/qa-caroline-achaintre$\underline{\text { baltic/ }}$

Tal como Sônia Gomes, Caroline Achaintre propõe ultrapassar os limites do fazer manual associado a uma técnica, fazendo com que a mão ocupe e explore novos territórios. Esta ideia está presente no seguinte testemunho da artista na sua entrevista:

Muitos artistas que incluem essas técnicas e métodos [tradicionais] nas suas obras de arte recorrem a outros para o fazerem, o que é totalmente aceitável. Mas isso geralmente significa que as peças foram traduzidas de um desenho ou descrição. Eu acho que muitas vezes algo se perde nesse processo de tradução, e as peças podem parecer bastante mecânicas ou como um artefato ilustrado. Muitas vezes as peças em que os artistas estão diretamente envolvidos no processo são mais expressivas, intensas e vivas. ${ }^{36}$

Também a artista austríaca Ingrid Wiener salienta a importância de ser ela a realizar as suas tecelagens, cujo processo de construção descreve como "pintar com lã", sublinhando a dimensão temporal e incerta dessa tarefa:

Eu definiria minha tecelagem de tapeçarias como pintura com fios. Mas pintar com fios é mais exigente do que pintar com um pincel, onde você sempre pode melhorar ou cancelar seu desenho apenas pintando por cima. Como disse Antoine de Rivarol: O movimento entre dois pontos fixos é a imagem do presente em movimento entre o passado e o futuro. O tecelão tecendo seu tecido faz o que ainda está para ser. Como tecelã, essa afirmação sempre terá significado para mim. Eu converso com o passado - se meu design permitir - e o primeiro fio é definido no presente, o segundo já é uma perspectiva para o futuro. Quando analisado linha por linha, apenas certas coisas no tecido são visíveis. O resto ainda está na minha imaginação. (...) Fazer a minha tecelagem é como pintar com lã, por isso, no início, nem sempre sei como ficará no final. ${ }^{37}$

\footnotetext{
${ }^{36}$ Ibidem, p. 333. Tradução nossa.

${ }^{37}$ Ibidem, p. 334. Tradução nossa.
} 
Nas propostas artísticas aqui apresentadas, a intenção de desconstruir e desafiar os limites das técnicas tradicionais do fazer manual constrói novos lugares para esse fazer. Apesar da diversidade de linguagens, parecenos que, em todas as propostas, há uma tentativa de entender o novo através das lentes do passado, construindo uma relação horizontal e reciprocamente permeável entre as duas realidades, e não uma relação de forças de poder.

\section{ofazer manual é político}

No contexto atual, em que a produção se mostra cada vez mais industrializada e impessoal, as estratégias aparentemente anacrônicas do fazer associadas a processos manuais e artesanais podem ser interpretadas como uma manifestação política de posicionamento relativamente aos meios de produção, bem como a questões sociais que permeiam uma sociedade contemporânea “(...) situadas dentro dos desafios da urbanidade, da globalização e do capitalismo num mundo pós-industrial e tecnologicamente-saturado"38. Muitos artistas estão conscientes das implicações políticas do seu trabalho e, ao invés de tentar recorrer a meios ostentosos e espetaculares, concentram intencionalmente as suas práticas em estratégias que valorizam o local, a lentidão e o artesanal, contrariando um modelo capitalista de produção que reforça relações hierárquicas de poder entre quem pensa e quem fabrica. A isto podemos chamar a "mão politizada", já presente nas dimensões do fazer anteriormente identificadas, mas que aqui destacamos por referência ao artista brasileiro Alexandre da Cunha.

A sua exposição "Fair Trade", apresentada no ano de 2011 na galeria Luísa Strina em São Paulo, ilustra bem esta dimensão. A expressão "Fair trade" ou "comércio justo" é um certificado que vem sendo cada vez mais utilizado nos países chamados desenvolvidos, para designar produtos adquiridos de países emergentes a preços sustentáveis, em que o produtor recebe uma remuneração considerada adequada, com o intuito de corrigir a exploração promovida pelo comércio internacional convencional. O comércio justo procura melhorar as condições de vida e de trabalho dos produtores, especialmente os pequenos produtores desfavorecidos, promovendo assim a equidade social, a proteção do ambiente e a segurança econômica. Entre outros trabalhos da exposição, é apresentado um conjunto de bordados em pedaços de tecidos de juta (figura 18) utilizados originalmente para ensacar produtos agrícolas de exportação. Estes objetos promovem um encontro entre o território ligado ao artesanato através da utilização de uma técnica tradicional (bordado) e o campo associado à arte contemporânea e à inovação conceitual. Para isso concorre também o fato de se conferir um valor estético a um material associado à indústria e ao trabalho operário (a juta), atribuindo-se-lhe um novo lugar enquanto “cenário" de um fazer que é personalizado, pensado e único.

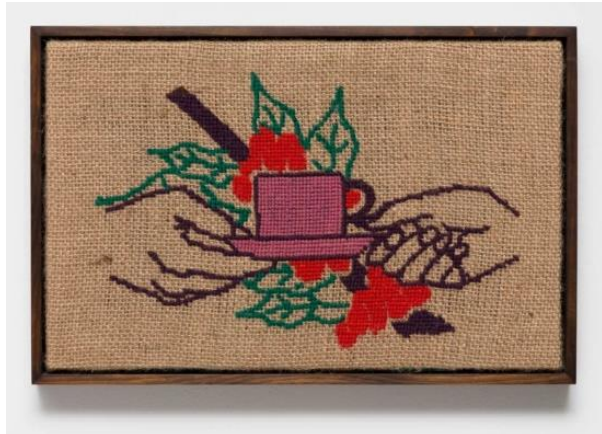

Figura 18: Alexandre da Cunha, "Fair trade XIV", bordado sobre saco de juta, colaboração com Luísa Strina, 30 x 47 cm, 2011. Fonte: https://www.galerialuisastrina.com.br/artistas/alexandre-da-cunha/

\footnotetext{
${ }^{38}$ BlACK, Anthea; BurISCH, Nicole. Craft Hard, Die Free: Radical Curatorial Strategies for Craftivism in Unruly Contexts. In: ADAMSON, Glenn (ed.). The Craft Reader. Oxford, New York: BERG, p. 609-619, 2010, p. 610. Tradução nossa.
} 
A produtora dos bordados apresentados foi a galerista, Luísa Strina, que ao longo de dois anos confeccionou manualmente os bordados exibidos, colaborando em pé de igualdade com o artista na sua produção. Subverte-se aqui a convencional relação de poder ou de exploração entre galerista e artista, e problematiza-se o processo de criação artística, no qual a galerista assumiu diversos papéis: artesã, artista, assistente de artista e galerista. $\mathrm{O}$ ato do fazer adquire aqui um lugar essencial para o entendimento da proposta. A transferência das mãos do artista para as mãos da galerista problematiza o fazer da obra, a relação entre quem a pensa e quem a faz, e a sua validade artística e cultural.

O seguinte testemunho da entrevista de Alexandre da Cunha sintetiza bem a ideia de que o artista como fazedor pode suscitar questionamentos acerca da realidade e introduzir uma outra ordem nas coisas:

(...) ao contrário de um artista que classicamente vai falar de inspirações mais eruditas, esse fazer do artesão e do, digamos, trabalhador comum, sempre teve uma influência forte no meu fazer e acho que tem um interesse sobre esses outros assuntos (a arquitetura, artes aplicadas, artesanato) como uma fonte de inspiração no trabalho. Mas eu acho que tem também num campo mais pessoal que é esse desejo de trazer o trabalho para esse lado quase de se igualar com outras atividades. O papel do artista nada mais é do que também o de um trabalhador. (...) Mas eu exploro a possibilidade de que ele, através da beleza dele e do appeal que o trabalho tem, ele possa também mudar essas outras coisas. (...) E eu gosto dessa ideia de que as pessoas que não conhecem arte contemporânea falem: “Ah, isso é um tapete.” É o primeiro encontro com o espectador que vem de um código que é universal. Aí depois as questões vêm. ${ }^{39}$

Em síntese, uma "mão politizada" é um fazer manual engajado politicamente por nele residir uma proposta de problematização social. No contexto atual de produção rápida e tecnologicamente complexa, a adoção de meios do fazer manual ultrapassa a necessidade técnica em busca de novos discursos politizados.

\section{Conclusão}

Ao longo do artigo, foram abordados os possíveis novos lugares ou dimensões do fazer manual na arte contemporânea a partir do testemunho e obras de dez artistas. Identificamos cinco dimensões: os novos diálogos com o corpo, a performance ou a "mão-em-ação", o fazer tradicional, o uso expansivo das técnicas tradicionais e a dimensão política do fazer manual ou "mão politizada". Em síntese, os novos modos de manualidade indicam, por um lado, uma ruptura relativamente aos fazeres manuais tradicionais e, por outro lado, uma permanência desses mesmos fazeres. Parece-nos que é nessa coabitação de linguagens e de forças que emerge uma potência estética que encontra na tradição novos modos de propôr o novo e o contemporâneo. Ao mesmo tempo, julgamos ser evidente nas propostas e no testemunho dos artistas a procura de um sentido de presença individual no mundo. Seja através da existência do corpo do artista ou do fazedor da obra, da evidenciação dos processos do fazer, do resgate dos meios do fazer manual que reclamam um tempo e dedicação alargados de quem produz, da subversão desses modos de atuação, ou ainda da reinvindicação de uma posição politizada no fazer, todas as abordagens parecem convergem para a emergência de uma relação íntima entre o fazer e o estar, traduzida num forte sentido de compromisso com o "eu" e o mundo.

\footnotetext{
${ }^{39}$ VIEIRA, op. cit., p. 325.
} 


\section{Referências}

ABRAMS, Loney. Sculpting the Landscape: Brie Ruais on Using Clay as a Metaphor for Land's Violent History.

Artspace: Artspace, Brooklyn, 28 set. 2017. Disponível em:

https://www.artspace.com/magazine/interviews_features/qa/sculpting-thelandscape-brie-ruais-on-using-clayas-a-metaphor-for-lands-violent-history-55026. Acesso em: 6 mar., 2018.

ADAMSON, Glenn. Thinking Through Craft. New York: Berg, 2007.

ADAMSON, Glenn; BRYAn-WILSON, Julia. Art in the Making: Artists and their Materials from the Studio to Crowdsourcing. London: Thames \& Hudson, 2016.

BlACK, Anthea; BuRISCH, Nicole. Craft Hard, Die Free: Radical Curatorial Strategies for Craftivism in Unruly Contexts. In: ADAMSON, Glenn (ed.). The Craft Reader. Oxford, New York: BERG, 2010, p. 609-619.

BuszeK, Elena (ed.). Extra/Ordinary - Craft and Contemporary Art. Durham, London: Duke University Press, 2011.

CRAWford, Matthew. The Case for Working with Your Hands. London: Penguin, 2009.

IPSEN, Lena. Lena Ipsen in conversation with Arna Óttarsdóttir. A+. Berlim, dez., 2018. Disponível em: https://www.xn--plus-poa.de/exhibitions/2019/arna-\%C3\%B3ttarsd\%C3\%B3ttir-a-soft-power/. Acesso em: 12 jan., 2019.

KRAUSS, Rosalind. Originality of the Avant-Garde and Other Modernist Myths. Cambridge, MA: MIT Press, 1985.

MARGETTS, Martina. Action Not Words. In: ChARNY, Daniel (ed.). Power of Making: The importance of being skilled. London: V\&A Publishing, p. 38-43, 2011.

McCullough, Malcolm. Abstracting Craft. The Practiced Digital Hand. Cambridge, Massachusetts e London: The MIT Press, 1996.

Merleau-Ponty, Maurice. Fenomenologia da Percepção. São Paulo: Martins Fontes, 1999.

NAPIER, John Russell. Hands. New Jersey: Princeton University Press, 1980.

OliviER, Valerie Cassel (ed.). Hand+Made: The Performative Impulse in Art and Craft. New York: Contemporary Arts Museum, Houston, 2010.

PINTO, Ana Estela de Sousa. A artista é mulher e negra, mas a arte é arte. Folha de São Paulo, São Paulo, 19 ago. 2017. Disponível em: https://www1.folha.uol.com.br/ilustrada/2017/12/1944244-a-artista-e-mulher-e-negramas-arte-e-arte-diz-sonia-gomes.shtml.Acesso em: 20 ago., 2017.

Polanyi, Michael. Personal Knowledge: Towards a Post-Critical Philosophy. New York: Harper \& Row, 1964. VIEIRA, Flávia. O Artista Contemporâneo enquanto Artesão - A Presença do Fazer Manual na Arte. 2019. Tese (Doutorado em Artes Visuais) - Instituto de Artes, Universidade Estadual de Campinas, 2019.

WILSON, Frank. The Hand: How its use shapes the brain, language, and human culture. USA: Vintage Books, 1998. 